\title{
REFLETINDO SOBRE O CUIDADO ODONTOLÓGICO E A RESPONSABILIDADE PARA COM A VIDA E O VIVER MAIS SAUDÁVEL DAS PESSOAS IDOSAS.
}

[Reflecting about oral health care and the responsibility for a better and healthy living of elderly people]

\author{
Ana Lúcia Schaefer Ferreira de Mello* \\ Alacoque Lorenzini Erdmann**
}

\section{INTRODUÇÃO}

O cuidado à saúde vem sendo um dos maiores desafios à sociedade moderna. Desafio para gerar oferta suficiente em adequado padrão de qualidade, que satisfaça uma demanda-de atenção continuamente mais diversificada e crescente. Desafio para democratizar o acesso das pessoas aos conhecimentos e práticas que a ciência desenvolve. Em tal contexto destacamos a necessidade de avançar na fundamentação e difusão do valor do cuidado à saúde enquanto ato de responsabilidade diante da vida e da aspiraçãodireito de um viver saudável.

Neste artigo tratamos de um fenômeno relevante no campo da saúde coletiva para o qual escassa atenção tem sido dada: a responsabilidade e o cuidado da saúde bucal daqueles que atingiram a idade avançada, geralmente fragilizados, para assegurar-Ihes 0 acesso universal a ações de promoção de saúde bucal, numa perspectiva de abordagem integral à pessoa em seu processo de melhor viver e envelhecer com saúde.

ETTINGER e MULLIGAN (1999) ressaltam a importância do diagnóstico, prevenção e tratamento das doenças que acometem a cavidade bucal e estruturas associadas que possam comprometer as funções de mastigação, deglutição e paladar na pessoa idosa. Estas limitações e suas

\footnotetext{
*Cirurgiã-dentista, Especialista em Odontogeriatria, Mestre em Saúde Bucal Coletiva, Aluna do curso de Doutorado em Enfermagem da UFSC, Bolsista CAPES.

**Professora Titular do Dpto Enf. UFSC e PEN/UFSC, Pesquisadora do CNPq. Doutora em Filosofia da Enfermagem/UFSC.
}

conseqüências, e tantas outras que afetam inclusive a sociabilidade, estão presentes no cotidiano da maioria dos idosos, penalizando, por óbvio, os pobres. Ademais, é também relevante considerar que os pacientes idosos portadores de outras doenças ou condições/limitações de caráter sistêmico e crônico, relacionadas tanto a problemas fisiológicos, físicos como psicológicos, requerem atendimento odontológico especial e integrado no cuidado preventivo e curativo de sua saúde geral.

Em seu aspecto particular, o cuidado à saúde bucal de idosos é caracterizado pela atenção especial ao atendimento preventivo e curativo de pacientes com doenças ou condições de caráter sistêmico e crônico associados a problemas fisiológicos, físicos ou psicológicos (SBOG, 2001), e inclui, segundo Ettinger e Mulligan (1999), pelo menos, o diagnóstico, a prevenção e o tratamento das doenças que acometem a cavidade bucal e estruturas associadas que possam comprometer as funções de mastigação, deglutição e paladar.

$\mathrm{O}$ resgate do cuidado odontogeriátrico, como componente indissociável do cuidado à saúde numa perspectiva de coletividade, e a sua efetiva incorporação na prática cotidiana estimulam reflexões e provocam algumas indagações: que dimensões de cuidado são importantes para o viver humano mais saudável? Os conhecimentos e procedimentos já estabelecidos do cuidado da saúde bucal materializam uma prática voltada para um viver saudável? Qual a extensão temporal do cuidado odontológico, particularmente o destinado às pessoas idosas? O cuidado odontológico permeia uma responsabilidade ética para com a vida, o futuro, o viver mais saudável ao longo da vida? 


\section{O CUIDADO ODONTOLÓGICO E O ENVELHECIMENTO HUMANO}

Inicialmente, vale enfatizar que envelhecer não é um problema, todos estamos envelhecendo em qualquer momento de nossas vidas e deveríamos ter a oportunidade de fazê-lo de uma maneira saudável e ativa (WHO, 1999). O envelhecimento é um processo natural e gradativo de alterações biológicas, psicológicas e no comportamento social ao longo da vida e cujo início ocorre antes mesmo do nascimento. Reflexo da evolução conceitual sobre a postura perante o envelhecimento, em 1995, a Organização Mundial de Saúde (OMS) alterou a denominação do seu Programa "Saúde dos idosos" para "Envelhecimento e saúde" e, em 2000, denominouo "Envelhecimento e curso de vida" (WHO, 2002).

O envelhecimento é um processo gradativo de alterações biológicas, psicológicas e sociais que acontece nos indivíduos ao longo da vida e cujo início ocorre antes mesmo do nascimento. Envelhecer não é um problema, mas uma parte natural do ciclo vital. Todos estamos envelhecendo em qualquer momento de nossas vidas e deveríamos ter a oportunidade de fazê-lo de uma maneira saudável e ativa (WHO, 1999).

De valor apreciável, a OMS publicou, em 1999, o documento "A life course perspective of maintaining independence in older age", no qual a "responsabilidade" é resgatada como categoria norteadora na apreciação do tema saúde e envelhecimento. Ressalta a importância de as pessoas tomarem a seu cargo a responsabilidade por determinadas posturas e comportamentos ("fatores individuais") durante a vida, de modo que sejam capazes de influenciar seu processo de envelhecimento adaptando-se a alterações tempodependentes. E em outra dimensão proclama a responsabilidade das organizações públicas e privadas e de seus agentes, pois suas decisões atuam sobre "fatores coletivos", em especial sócioeconômicos e ambientais, afetando e condicionando a saúde e o envelhecimento das pessoas.

Nossa reflexão parte de uma premissa: a de que a melhor maneira de assegurar boa saúde para as futuras coortes de indivíduos idosos é prevenindo doenças e promovendo saúde através do curso da vida. Aceita esta premissa, a responsabilidade ética associada ao cuidado odontológico ao longo da vida e dos deveres que a ela correspondem, vai muito além da usual atenção tópica, episódica, emergencial, e nos coloca diante de titulares de direito a uma atenção contínua e sistematizada, a ser proporcionada com responsabilidade por uma rede de proteção a ser tecida. Nesta perspectiva, o cuidado odontológico na prática cotidiana, para atender aos princípios de eficácia e efetividade, deverá emanar do exercício da responsabilidade, que Ihes corresponda, nas esferas individual, familiar, organizacional e público-estatal.

A literatura tem dirigido maior atenção à descrição do quadro epidemiológico da saúde bucal de idosos, sobressaindo-se o olhar sobre os idosos institucionalizados, pois estudos têm mostrado o aumento da demanda por instituições geriátricas de longa permanência (BRAVO et al., 1999; OMS, 1974; VIEIRA, 2003) nas quais a situação de dependência, determinada pela incapacidade e também pela necessidade, requer ajuda indispensável para a realização de atos elementares da vida. SCHNEIDER e GURALNIK (1990) projetaram para o ano 2040 de 3,6 a 5,9 milhões de norte-americanos residindo em casas geriátricas. Também indicaram que a proporção de pessoas idosas que permanecem em seus lares necessitando de auxílio de terceiros nas atividades diárias, aumenta acentuadamente conforme a faixa etária: de $10 \%$ entre 65 a 74 anos, para $37 \%$ nos maiores de 85 anos.

No Brasil, a carência de estudos sobre a institucionalização de idosos dificulta inferências acerca do assunto. Embora muitos idosos sejam institucionalizados por problemas físicos e mentais que causam dependência, a miséria, o abandono familiar e a omissão governamental geralmente estão relacionados ao processo de institucionalização (CHAIMOWICZ; GRECO, 1999; WALDOW, 1987).

Vários estudos têm demonstrado evidências de negligência permanente do cuidado odontológico em instituições geriátricas (FISKE; LLOYD, 1992; JOKSTAD; AMBJORNESEN; EIDE, 1996; KNABE; KRAM, 1997; MELLO, 2001).

Em pesquisa que uma das autoras efetuou (MELLO, 2001) em instituições geriátricas privadas, 
em Porto Alegre, o cuidado odontológico apresentou-se bastante insatisfatório, resultado de procedimentos de higiene bucal empíricos, desassociados de adequada orientação técnica, especialmente aquela de natureza odontogeriátrica. As práticas não seguiam qualquer tipo de protocolo e não constituíam parte integrante da rotina das casas geriátricas pesquisadas. A presença de profissionais da odontologia na supervisão e orientação da coletividade residente era rara. Os procedimentos de saúde bucal costumeiramente eram deixados sob o exclusivo critério dos cuidadores e as instituições, numa visão reducionista do processo, não se percebiam responsáveis pela provisão do cuidado odontológico. Também não existia programa público específico de atenção odontológica para idosos institucionalizados. O estudo encontrou 111 instituições geriátricas que acolhiam 2113 idosos. A taxa de institucionalização era de 1,44\%. Observou-se que o tratamento odontológico é solicitado somente em caso de emergência e o idoso ou a família deve custeá-lo.

Em Florianópolis, no primeiro semestre de 2003, no âmbito de projeto de extensão universitária da UFSC em três instituições geriátricas filantrópicas, levantamento procedido por uma das autoras registrou a presença de 98 pessoas idosas. Tratamento clínico era prestado em apenas uma casa por um cirurgião-dentista voluntário. Nenhuma das residências possuía um protocolo definido de atenção e assistência que garantisse uma rotina de cuidado em saúde bucal, ao menos de higiene dentária e das próteses.

A observação simultânea da melhoria na saúde bucal da população infantil (WHO, 2002) e da elevação da expectativa de vida da população, permite deduzir o crescimento cumulativo do número de pessoas necessitando de cuidado para a manutenção da sua saúde bucal durante o curso da vida. Nesta população amplia-se o grupo de idosos, e, neste, aqueles que necessitam de cuidado odontológico especial em casa ou em instituições geriátricas.

\section{A ÉTICA DA RESPONSABILIDADE}

A sociedade está defrontada com um fenômeno relevante no campo da saúde coletiva, para o qual pouca atenção tem sido dada. Irrecusável o cuidado àqueles que atingiram a idade avançada mais fragilizados e imprescindível uma abordagem integral à pessoa em seu processo de melhor viver e envelhecer com qualidade, proporcionado o acesso universal a ações de promoção de saúde bucal ao largo de toda sua existência.

A constatação destas carências e deficiências colhidas na literatura e nas experiências pessoais, confrontam-se com os valores maiores atribuídos à preservação da vida humana e são impeditivas de um viver saudável. Este ambiente de pouco compromisso organizacional privado, institucional público, e até familiar, no qual acontece o cuidado odontológico, sugere a oportunidade de examinarmos mais de perto a responsabilidade enquanto categoria nuclear, central, no desempenho de tais atividades com as pessoas idosas.

A responsabilidade perpassa as dimensões quantitativa e qualitativa do cuidado, a dimensão pessoal e sobretudo a dimensão social. Portanto, é um reducionismo perverso vê-la apenas na relação cuidador-paciente. É indispensável cautela evitando o equívoco de lançar um olhar unidirecional sobre os trabalhadores da saúde e os cuidadores, em sentido estrito. É imprescindível contemplar "esferas de cuidado", que interligadas contribuem para a construção/manutenção da condição de saúde bucal. O olhar deve rastrear a responsabilidade enquanto atributo nas esferas: pessoal (do idoso consigo); atributo profissional (dos profissionais que efetivamente cuidam dos idosos); atributo institucional/organizacional (da organização que se propõe a cuidar, da que emprega idosos, da que fabrica medicamentos e outros insumos, da que opera plano de saúde bucal, etc.); atributo estatal/governamental do Estado como dever/compromisso da sociedade e dos governos pela geração/implementação/regulação de políticas); atributo familiar (compromisso solidário das pessoas que lhe devem afeto); atributo da academia (do conhecimento posto a serviço das pessoas). Só esta abordagem compreensiva e sistêmica pode contribuir para a construção de uma rede de proteção, tanto mais resistente quanto melhor configurada cada esfera de responsabilidade. 
A expressão "responsabilidade" tem sua gênese no verbo responder. Segundo os estudos de Santos (2002), o termo responsabilidade se origina da expressão latina re spondeo (re = prefixo de anterioridade; spondeo = esposar, assumir), ou seja, assumir antecipadamente pelo que vai fazer e, extensivamente, significa a habilidade e a capacidade de assumir conscientemente todas as conseqüências das próprias ações e omissões.

Em ética, responsabilidade significa assumir (tomar cargo) o que foi feito frente ao afetado. Disto é corolário o cuidar, em sua mais ampla acepção, de outro ser humano quando este está ameaçado em sua vulnerabilidade.

A ética aplicada atribui responsabilidades aos indivíduos a partir do pressuposto que cada ato tenha sido livremente escolhido por um agente moral, que sempre é responsável por suas decisões e conseqüências (SCHRAMM; KOTTOW, 2001).

Schramm (2003), numa visão antropocêntrica, afirma que a responsabilidade está no cerne da ética, pois os objetos de avaliação ética são justamente os atos escolhidos livremente e pelos quais podemos ser cobrados.

Segundo MORIN; NAIR (1997),

“...o problema da responsabilidade deve ser colocado em termos complexos. De um lado, cada um deve reconhecer-se responsável por suas palavras, por seus escritos, por seus atos. De outro, tomando como base a ecologia da ação, ninguém é responsável pelo modo como suas palavras são entendidas, como seus escritos são compreendidos, como seus atos são mal interpretados, distorcidos. Cada um, em suma, é 100\% responsável e 100\% irresponsável."

De outro modo, Morin (1986) enfatiza que a ética não pode vencer a complexidade, isto é, a pluralidade, a contradição, a incerteza, os pontos vazios. Ética contém injunções múltiplas, de níveis diferentes que podem ser complementares, concorrentes ou antagônicas. Assim, a ética não escapa à complexidade antropossocial, cuja ecologia da ação escapa à ação moral.

Morin; Nair (1997) discorrendo sobre responsabilidade nos remete a Hans Jonas quando apontam:

"Há uma outra responsabilidade, que é oriunda de nossa comunidade de destino planetário. É ela que sempre relembra nossa parcela de responsabilidade nesse destino comum, e não somente no que diz respeito ao presente, mas também ao futuro."

É instigante a abordagem da "responsabilidade" em Hans Jonas ao situá-la numa perspectiva de futuro. Afinal, a melhor qualidade de vida na fase idosa dependerá em boa medida do cuidado responsável da saúde ao longo da vida. $\mathrm{E}$ isto, por óbvio, não se circunscreve ao auto-cuidado e as suas efetivas possibilidades.

Alemão, Jonas (1902-1993) teve sua vida marcada pelos horrores da segunda grande guerra. A mãe morreu em Auschwitz. Optou pelo exílio logo que os nazistas alcançaram o poder. Durante o conflito lutou como soldado voluntário da brigada judia no exército inglês. Depois da guerra, dedicado à academia, viveu em Israel, Canadá e Estados Unidos. Sua formação intelectual foi influenciada diretamente por Martin Heiddeger (1889-1976), o filósofo da "ontologia do ser", seu mestre em Freiburg e Marburg. Em 1966, publicou obra intitulada "O fenômeno da vida: rumo a uma biologia filosófica", e ali afirmou que a "ontologia é o fundamento da ética" (JONAS, 1995). Na década de 70, já aposentado de suas tarefas docentes e com a idade avançada Jonas dirige seu foco de atenção para os problemas éticos da era moderna, principalmente àqueles advindos dos avanços da tecnologia.

O êxito de "O princípio da responsabilidade: ensaio de uma ética para a civilização tecnológica", publicado em 1979, o tornou então conhecido e referenciado no mundo.

O princípio da responsabilidade é a proposta de Hans Jonas para a adoção de uma nova ética em face dos novos desafios impostos pela modificação do caráter da ação humana nos dias atuais. Em suas reflexões, as premissas éticas conhecidas e aplicadas até recentemente já não podem ser mais consideradas ante à mudança da natureza da ação humana. Os fundamentos éticos antropocêntricos, que consideram o ser humano como essência e não como objeto, desvinculados de questões extra-humanas, proximistas e imediatistas, para os quais bem e mal e seus efeitos tem um curto raio de alcance/efeito, são abalados/ questionados pelo pensamento de Hans Jonas. Segundo Zancanaro (2000), Jonas não nega o antropocentrismo, mas suas críticas à ética 
tradicional, kantiana, têm por objetivo mostrar as limitações do agir individual e do seu pouco poder de transformação, num mundo onde as decisões são coletivas.

A "ética da responsabilidade" foi trabalhada inovadoramente por Max Weber no começo do século passado, referindo-se à responsabilidade de cientistas e políticos. A retomada desta reflexão por Hans Jonas, porém mais aprofundada, tanto nos níveis individuais como coletivo, representou na visão de Schramm (2003) a primeira análise sistemática da responsabilidade como princípio moral. É que Jonas propõe um novo imperativo ético, incondicional, fundamentado na ontologia do ser, mais adequado às ações humanas recentes $e$ dirigido aos novos tipos de sujeito(s) da ação. Assim, a partir do imperativo categórico de Kant "Trabalhe de tal modo que possas querer também que tua máxima se converta em lei universal", Hans Jonas deriva seu imperativo: "Trabalhe de tal modo que os efeitos de tua ação sejam compatíveis com a permanência da vida humana na Terra", ou em outros termos, "Não ponhas em perigo as condições da continuidade indefinida da humanidade na terra", ou ainda, "Inclua em tua escolha presente, como objetivo também do teu querer, a futura integridade do homem" (JONAS, 1995).

Segundo Siqueira (2000), Jonas propõe uma nova ética, considerando que o alcance das prescrições até então vigentes, calcadas no modelo kantiano, ficam reduzidas ao âmbito da relação com o próximo, numa "insatisfatória premissa antropocêntrica e contemporânea". O que Jonas quer é uma ética voltada para o futuro, estendendo nossos compromissos morais de tal modo que alcance as gerações que estão por vir, responsabilizando-nos também pelos cuidados com a natureza extra-humana.

De acordo com Garrafa (2003), "a filosofia, por meio da chamada "ética aplicada", pode dizer várias coisas concretas: que tipo e formas de vida são melhores do que outras, que coisas trazem benefícios ou danos." A apropriação do princípio da responsabilidade de Jonas, como perspectiva teórico-filosófica, para abordar o fenômeno do cuidado da saúde bucal das pessoas, no quadro de um viver saudável ao longo da vida, parece ser um caminho interessante e inovador, no que diz respeito tanto à compreensão, quanto à interpretação do fenômeno.

Na expressão de Zancanaro (2000), sob a inspiração de Jonas, o "fim do ser" é a vida, mas não pode ser entendida como um mero viver, porque outros animais também vivem; é um viver com dignidade, qualidade e felicidade. É simplesmente existir e continuar existindo indefinidamente. A vida como bem concreto clama por respeito, não por imposição normativa ou prescritiva, mas por ser o "bem substancial", cuja exigência quanto ao viver presente e futuro é dele mesmo, não por causa de um desejo, necessidade ou escolha. Jonas (1995) reporta-se à "responsabilidade primordial do cuidado paterno" como sendo "a primeira que todo o mundo experimentou em si mesmo", e conclui que "neste paradigma fundamental se faz clara e de maneira a mais convincente a vinculação da responsabilidade ao que é vivo". Nesse passo, assevera que o diferencial característico do ser humano, o fato de que só ele pode ter responsabilidade, implica cada humano ser responsável também por outros iguais a ele, e estes por sua vez também serem possíveis sujeitos de responsabilidade. De tal maneira que "genericamente, a reciprocidade está sempre presente", pois qualquer pessoa que tenha responsabilidade por alguém, por viver entre homens, é sempre também responsabilidade de alguém. Assim "o protótipo da responsabilidade é a responsabilidade do homem pelo homem". Ainda que não exercida nem sentida, o autor vê a responsabilidade insculpida na essência do ser humano, indissociável da condição humana, e então, como corolário, "no ser do homem existente está contido de maneira totalmente concreta um dever..., uma obrigatoriedade objetiva na forma de responsabilidade externa".

O conceito de responsabilidade em Jonas (1995) implica o dever; primeiro o de "dever-ser" de algo, depois, o de "dever-fazer" a alguém em resposta a este dever-ser. $E$ segue, "responsabilidade é o cuidado, reconhecido como dever, por outro ser cuidado que, dada a ameaça de sua vulnerabilidade, se converte em preocupação". A pergunta norteadora sugerida por Jonas é: o que ocorrerá a isso se eu não me ocupar dele? Quanto mais obscura a resposta, tanto mais clara será a responsabilidade".

Zancanaro (2000) traduz o pensamento de 
preservação como parte intrínseca da responsabilidade com o futuro. Promover a educação, a saúde, a conservação do meio ambiente, a ética como política pública, é uma exigência do agir responsável com o amanhã, pois o agir e seu efeito estão implicados com o bem intrínseco". "Preservar o "bem substancial" é uma ação responsável porque nela estão implicados o respeito e a continuidade do frágil e do vulnerável."

Retomando Morin (1986), a consciência da responsabilidade passa pela responsabilidade moral de cada ser humano de saber ver e saber pensar o seu pensamento, no qual a responsabilidade não exime a irresponsabilidade da aposta, do risco, do perigo, ou seja, passa pelo mundo subjetivo dos valores entre a verdade e o relativismo, entre a consciência da responsabilidade moral e a irresponsabilidade dos riscos.

A consciência da responsabilidade pelo cuidado odontológico deve considerar que a antecipação da ameaça, a predição do dano psicoorgânico, o enunciado dos problemas potenciais podem "contribuir para tornar nossa ação moral, já que nela está implicada a vida". Será que esta consciência está presente nas pessoas envolvidas neste cuidado?

\section{CONSIDERAÇÕES FINAIS}

A ética da responsabilidade para com o futuro "investe na globalidade do ser, na singularidade e peculiaridade do ser humano." (ZANCANARO, 2000). Então, o direito das pessoas a um viver saudável impõe o afastamento de qualquer forma de discriminação e recomenda uma atuação coordenada, de base comunitária, eficaz, multiprofissional, e que dê especial apoio aos mais fragilizados, ou seja, aos que se encontram mais vulneráveis frente às condições de vida e de saúde.

O que se deseja é lançar um desafio e propor o exercício contínuo da responsabilidade intrínseca ao cuidado à saúde bucal, proporcionando um melhor viver ao ser humano idoso, individualmente e nas suas relações com as pessoas e o meio ambiente. Toda ação deve estar inserida num contexto de promoção de saúde para, conseqüentemente, evitar-se a negligência continuada.
A preservação da vida como valor maior e como meta inantigível, mas sempre perseguida, exige o conhecimento e a compreensão do estado do cuidado odontológico das/para as pessoas na perspectiva do curso da vida, bem como das que chegaram à fase idosa mais frágeis e dependentes, muitas vivendo em novas coletividades, institucionalizadas.

Conhecimento e compreensão também dos fatores intervenientes na provisão deste cuidado, e os limites e possibilidades de melhores práticas de saúde, de práticas eficientes e resolutivas de recuperação e manutenção da saúde bucal, tendo em vista a possibilidade de um viver mais saudável na perspectiva da continuidade e dignidade da vida, o "bem essencial" a preservar.

Refletir sobre a categoria responsabilidade teórico-filosóficos que embasem a compreensão e a interpretação dos fenômenos relativos ao cuidado à saúde bucal de pessoas idosas e de materializar uma prática voltada para um viver saudável. Esta será uma contribuição para que o cuidado odontológico também permeie uma responsabilidade ética para com a vida, o futuro, o viver mais saudável. Os imperativos formulados por Hans Jonas que fundamentam o princípio da ética da responsabilidade permitem o resgate do valor do cuidado à saúde bucal enquanto ato de responsabilidade diante da vida e da efetivação do direito de um viver saudável.

ABSTRACT: The article presents a reflection about some questions that are involved with oral health care provided to elderly people according to the ethic of responsability of Hans Jonas. Considering the oral health conditions of elderly people, the article discuss the dimensions of care and reflects if the knowledge and practices of oral health care are compromised with an ethics of responsibility of life and with a better and healthy living.

KEY-WORDS: Ethics dental; Oral health; Aged.

\section{REFERÊNCIAS}

BRAVO, G. et al. Correlates of care quality in long term care facilities: a multilevel analysis. J. Gerontol. B Psychol. Sci. Soc. Sci., Washington, v. 54, n.3, p.180-188, May 1999. 
CHAIMOWICZ, F.; GRECO, D.B. Dinâmica da institucionalização de idosos em Belo Horizonte, Brasil. Rev. Saúde Publ., São Paulo, v. 33, n. 5, p. 454-460, out. 1999.

ETTINGER, R.L.; MULLIGAN, R. The future of dental care for the elderly population. J. Calif. Dent. Assoc., Sacramento, v.27, n.9, p.687-692, Sept. 1999.

FISKE, J.; LLOYD, H.A Dental needs of the residents and carers in elderly people's homes and carers' atitudes to oral health. Eur. J. Prosthodont. Rest. Dent., v.1, n.2, p.91-95, 1992.

GARRAFA, V. Reflexão sobre políticas públicas brasileiras de saúde à luz da bioética. In: FORTES, P.A.C.; ZOBOLI, E.L.C.P. Bioética e saúde pública. São Paulo: Loyola, 2003. 167p.

JONAS, H. El principio de la responsabilidad: ensayo de una ética para la civilización tecnológica. Barcelona: Herder, 1995.

JOKSTAD, A.; AMBJORNSEN, E.; EIDE, K.E. Oral health in institutionalized elderly people in 1993 compared with in 1980. Acta Odontol. Scand., Oslo, v.54, n.5, p.303-308, Oct. 1996.

KNABE, C.; KRAM, P. Dental care for institutionalized geriatric patients in Germany. J. Oral Rehabil., Oxford, v.24, n.12, p.909-912, Dec. 1997.

MELLO, A.L.S.F., PADILHA, D.M.P., RODRIGUES, G.S., BENNETT, G. Casas geriátricas e negligência odontológica em Porto Alegre, Brasil. In: REUNIÃO ANUAL DA SOCIEDADE BRASILEIRA DE PESQUISA ODONTOLÓGICA, 18., Águas de Lindóia, 2001. Anais... Águas de Lindóia : SBPqO, 2001. 208 p., p.120.

MELLO, A.L.S.F. Cuidado odontológico provido a pessoas idosas residentes em instituições geriátricas de pequeno porte em Porto Alegre - RS: a retórica, a prática e os resultados. 2001. Dissertação (Mestrado em Odontologia) Faculdade de Odontologia, Universidade Federal do Rio Grande do Sul, Porto Alegre.
MORIN, E. Para sair do século XX. Rio de Janeiro: Nova Fronteira, 1986

MORIN, E. e NAIR, S. "A ética do sujeito responsável - Da incerteza democrática à ética política", in: Une politique de civilisation, Paris: Ed. Arléa, 1997, p.157-185. (traduzido por Edgard de Assis Carvalho).

ORGANIZACION MUNDIAL DE LA SALUD. Planificación y organización de los servicios geriátricos. Ginebra: OMS, 1974. 51p. (Informes Técnicos, 548).

SANTOS, N.Q. O uso indiscriminado de antibióticos e a ecologia das bactérias antibiótico-resistentes associadas à problemática da infecção hospitalar: a luz da ética de responsabilidade de Hans Jonas. 2002. Tese (Doutorado em Enfermagem) - Universidade Federal de Santa Catarina, Florianópolis.

SCHNEIDER, E. L.; GURALNIK, J.M. The aging of America: impact on health care costs JAMA, Chicago, v.263, n.17, p.2335-2340, May 1990.

SCHRAMM, F.R. A bioética da proteção em saúde pública. In: FORTES, P.A.C.; ZOBOLI, E.L.C.P. Bioética e saúde pública. São Paulo: Loyola, 2003. 167p.

SCHRAMM, F. R., KOTTOW, M. Princípios bioéticos en salud pública: limitaciones y propuestas. Cad. Saúde Pública, Rio de Janeiro, v.17, n.4, p.949956, jul/ago, 2001.

SIQUEIRA, J. E.Tecnologia e medicina entre encontros e desencontros. Bioética, v.8, n.1, p. 55$67,2000$.

VIEIRA, E. B. Instituições geriátricas: avanço ou retrocesso?. Rio de Janeiro: Revinter, 2003. 99p.

ZANCANARO, L. Cuidando do futuro da vida humana: a ética da responsabilidade de Hans Jonas. $O$ mundo da Saúde, São Paulo, v.24, n.4, p. 310-320, jul/ago, 2000. 
WALDOW, V. R. Determinação do nível de dependência em enfermagem junto a idosos institucionalizados de Porto Alegre/RS. Rev. Gaúcha Enf., Porto Alegre, v.8, n.1, p.46-73, 1987.

WORLD HEALTH ORGANIZATION. A life course perspective of maintaining independence in older age. Genebra: WHO, 1999.
WORLD HEALTH ORGANIZATION. Active ageing: a police framework. Genebra: WHO, 2002.

ENDEREÇO DAS AUTORAS: Rua: Bernardo Staviski, 357 Campina do Siqueira.CEP 80730-240 Curitiba - Paraná Tel.:335-7206/ 9973-3194 E-Mail: dpasqual@rla01.pucpr.br 